\title{
Safety and Efficacy of Pedicle Screws and Titanium Mesh Cage in the Treatments of Tuberculous Spondylitis of the Thoracolumbar Spine
}

\author{
Jae Chul Lee, Yon-II Kim, Byung-Joon Shin \\ Department of Orthopedic Surgery, Soonchunhyang University Hospital, Seoul, Korea
}

Study Design: This is a retrospective series.

Purpose: We wanted to analyze the safety and effectiveness of using the newer generation metallic implants (pedicle screws and/or titanium mesh) for the treatment of tuberculous spondylitis.

Overview of the Literature: There have been various efforts to prevent the development of a kyphotic deformity after the treatment of tuberculous spondylitis, including instrumentation of the spine. Pedicle screws and titanium mesh cages have become more and more popular for treating various spinal problems.

Methods: Twenty two patients who had tuberculous spondylitis were treated with anterior radical debridement and their anterior column of spine was supported with a tricortical iliac bone graft (12 patients) or by mesh (10 patients). Supplementary posterior pedicle screw instrumentation was performed in 17 of 22 patients. The combination of surgeries were anterior strut bone grafting and posterior pedicle screws in 12 patients, anterior titanium mesh and posterior pedicle screws in 5 patients and anterior mesh only without pedicle screws in 5 patients. The patients were followed up with assessing the laboratory inflammatory parameters, the serial plain radiographs and the neurological recovery.

Results: The erythrocyte sedimentation rate and C-reactive protein levels were eventually normalized and there was no case of persistent infection or failure to control infection in spite of a mettalic implant in situ. The overall correction of kyphotic deformity was initially 8.9 degrees, and the loss of correction was 6.2 degrees. In spite of some loss of correction, this technique effectively prevented clinically significant kyphotic deformity. The preoperative Frankel grades were B for 1 patient, $\mathrm{C}$ for 4, $\mathrm{D}$ for 4 and $\mathrm{E}$ for 13. At the final follow-up, 7 of 9 patients recovered completely to Frankel grade $\mathrm{E}$ and only two patients showed a Frankel grade of D.

Conclusions: Stabilizing the spine with pedicle screws and/or titanium mesh in patients with tubercuous spondylitis effectively prevents the development of kyphotic deformity and this did not prevent controlling infection when this technique was combined with radical debridement and anti-tuberculous chemotherapy.

Key Words: Tuberculous spondylitis, Pedicle screw, Titanium mesh

\section{Introduction}

Tuberculous spondylitis is still prevalent in the underdeveloped and developing countries. Even in the developed countries, the increased number of immunocompromised patients has precipitated a resurgence of Mycobacterium tuberculosis infections of the spine. The development of anti-tuberculosis chemotherapy has revolutionized the treatment of spinal tuberculosis, but chemotherapy alone may induce a residual kyphotic deformity and neurologic complications after the treatment.

Received Oct 20, 2008; 1st revised Nov 11, 2008; accepted Nov 12, 2008

Corresponding author: Byung-Joon Shin, MD

Department of Orthopedic Surgery, Soonchunhyang University Hospital

657 Hannam-dong, Yongsan-gu, Seoul 140-743, Korea

Tel: +82-2-709-9051, Fax: +82-2-796-3682, E-mail: schsbj@hosp.sch.ac.kr 
Since Hodgson and Stock first reported on anterior debridement and arthrodesis in the 1960' $\mathrm{s}^{1}$, this has been advocated as the treatment of choice for tuberculosis of the spine $^{2,3}$. However, the problems with this treatment were the long period of bed rest and external immobilization, the anterior strut graft tended to fail and a kyphotic deformity commonly occurred when more than two disc spaces were involved ${ }^{3}$. Therefore, many surgeons have used various kinds of metallic instrumentation for preventing kyphosis.

It has been generally believed that instrumentation introduces a metallic foreign body that can become a focus of organisms and cause the persistence of musculoskeletal infection. However, many surgeons have tried to use spinal instrumentation posteriorly or even anteriorly in the patients who suffer with tuberculous infection of the spine, and these surgeons reported the effectiveness of preventing progressive kyphosis after surgery ${ }^{4.9}$. In this current study we report on our experience of using newer generation implants, such as pedicle screws and titanium mesh, for treating tuberculous spondylitis of thoracolumbar spine and we analyze their safety and effectiveness.

\section{Materials and Methods}

\section{Patient population}

Twenty-two patients who underwent surgery and were stabilized by pedicle screws or titanium mesh for tuberculous spondylitis and who had been followed up for more than 2 years were included in this study. There were 9 male and 13 female patients and their average age at the time of surgery was 44 years (range, 20 to 70 years). The average follow-up was 40 months (range, 24 to 156 months). The involved regions of the spine were the thoracic region in 11 patients, the thoracolumbar region in 5 and the lumbar region in 7 . The involved number of segments was one in 6 patients, 2 in 9 patients and more than 3 in 7 patients, and the average number of involved segments was 2.3 segments (Table 1).

\section{Antituberculous chemotherapy}

Anti-tuberculous combination chemotherapy was started

Table 1. Summary of clinical data of the 39 patients with spinal tuberculosis

\begin{tabular}{|c|c|c|c|c|c|c|c|c|c|c|c|c|c|}
\hline \multirow[t]{2}{*}{$\begin{array}{l}\text { Patient } \\
\text { Number }\end{array}$} & \multirow[t]{2}{*}{$\begin{array}{c}\text { Age } \\
\text { (years) }\end{array}$} & \multirow[t]{2}{*}{ Gender } & \multirow[t]{2}{*}{$\begin{array}{c}\text { Involved } \\
\text { level }\end{array}$} & \multirow{2}{*}{$\begin{array}{c}\text { Removed } \\
\text { number } \\
\text { of discs }\end{array}$} & \multirow[t]{2}{*}{$\begin{array}{l}\text { Number of } \\
\text { corpectomy }\end{array}$} & \multicolumn{3}{|c|}{ Kyphosis (degree) } & \multicolumn{2}{|c|}{$\begin{array}{c}\text { Neurologic } \\
\text { grade (Frankel) }\end{array}$} & \multicolumn{2}{|c|}{ Implant } & \multirow[t]{2}{*}{$\begin{array}{c}\text { Follow-up } \\
\text { (month) }\end{array}$} \\
\hline & & & & & & Preop. & Postop. & Final & Preop. & Final & Anterior & Posterior & \\
\hline 1 & 20 & $\mathrm{~F}$ & T8-T9 & 1 & 0 & 27 & 20 & 24 & $\mathrm{E}$ & $\mathrm{E}$ & Mesh & & 30 \\
\hline 2 & 23 & M & L4-L5 & 2 & 1 & -12 & -14 & -7 & E & $\mathrm{E}$ & & PS & 37 \\
\hline 3 & 27 & M & L3-L4 & 1 & 0 & 4 & -20 & -16 & $\mathrm{E}$ & $\mathrm{E}$ & & PS & 30 \\
\hline 4 & 27 & M & L1-L2 & 1 & 0 & 29 & -2 & 13 & $\mathrm{D}$ & $\mathrm{E}$ & & PS & 30 \\
\hline 5 & 28 & $\mathrm{~F}$ & T12-L1 & 2 & 1 & 18 & 9 & 8 & $\mathrm{E}$ & $\mathrm{E}$ & Mesh & PS & 52 \\
\hline 6 & 28 & M & T5-T6 & 2 & 1 & 30 & 27 & 35 & $\mathrm{E}$ & $\mathrm{E}$ & Mesh & PS & 24 \\
\hline 7 & 31 & $\mathrm{~F}$ & T6-T9 & 2 & 1 & 40 & 32 & 35 & D & $\mathrm{E}$ & & PS & 36 \\
\hline 8 & 31 & $\mathrm{~F}$ & L2-L5 & 3 & 2 & -13 & -29 & -24 & $\mathrm{E}$ & $\mathrm{E}$ & Mesh & PS & 24 \\
\hline 9 & 38 & M & T5-T8 & 1 & 0 & 26 & 26 & 32 & E & $\mathrm{E}$ & & PS & 48 \\
\hline 10 & 39 & $\mathrm{M}$ & T10-T12 & 2 & 1 & 45 & 28 & 31 & E & $\mathrm{E}$ & & PS & 24 \\
\hline 11 & 44 & $\mathrm{~F}$ & T8-T11 & 5 & 4 & 39 & 37 & 42 & $\mathrm{C}$ & $\mathrm{E}$ & Mesh & PS & 131 \\
\hline 12 & 44 & $\mathrm{~F}$ & T11-L1 & 2 & 1 & 26 & 13 & 20 & E & $\mathrm{E}$ & & PS & 40 \\
\hline 13 & 48 & $\mathrm{~F}$ & T8-T12 & 1 & 0 & 48 & 31 & 38 & $\mathrm{D}$ & $\mathrm{E}$ & & PS & 24 \\
\hline 14 & 50 & $\mathrm{~F}$ & L4-L5 & 2 & 1 & -13 & -22 & -18 & E & $\mathrm{E}$ & & PS & 24 \\
\hline 15 & 53 & $\mathrm{~F}$ & L2-L4 & 2 & 1 & -26 & -23 & -11 & $\mathrm{C}$ & $\mathrm{E}$ & & PS & 156 \\
\hline 16 & 60 & $\mathrm{~F}$ & T11-L1 & 2 & 1 & 32 & 11 & 32 & $\mathrm{E}$ & $\mathrm{E}$ & Mesh & PS & 24 \\
\hline 17 & 63 & $\mathrm{~F}$ & T11-L1 & 1 & 0 & 21 & 20 & 25 & $\mathrm{C}$ & $\mathrm{E}$ & & PS & 30 \\
\hline 18 & 65 & M & L4-L5 & 2 & 1 & -23 & -23 & -21 & E & $\mathrm{E}$ & & PS & 24 \\
\hline 19 & 65 & M & T7-T10 & 3 & 2 & 39 & 36 & 47 & $\mathrm{D}$ & $\mathrm{D}$ & Mesh & & 24 \\
\hline 20 & 65 & $\mathrm{~F}$ & L3-L4 & 1 & 0 & -11 & -21 & -14 & $\mathrm{E}$ & $\mathrm{E}$ & Mesh & & 24 \\
\hline 21 & 67 & M & T6-T7 & 1 & 0 & 9 & 8 & 8 & $\mathrm{C}$ & $\mathrm{E}$ & Mesh & & 28 \\
\hline 22 & 70 & $\mathrm{~F}$ & Т9-Т10 & 1 & 0 & 14 & 10 & 12 & B & $\mathrm{D}$ & Mesh & & 24 \\
\hline
\end{tabular}

Mesh: titanium mesh cage, PS: pedicle screw. 
as soon as the diagnosis of tuberculous spondylitis was made or when it was highly suspected. A combination of isoniazid, ethambutol, rifampicin and pyrazinamide was given for minimum 1 year and this was continued until the erythrocyte sedimentation rate and the C-reactive protein level were normalized. The average duration of anti-tuberculous chemotherapy was 18 months (range, 12 to 22 months). Seven patients who underwent surgery after failed conservative treatment received the chemotherapy for an average of 5 months (range, 1 to 11 months) preoperatively.

\section{Indications for surgery}

The operative indications were neurologic deficits, severe back pain and/or radicular pain that was resistant to conservative treatment, a persistent huge cold abscess, instability or progressive kyphosis, and severe bone destruction extending to more than 2 consecutive vertebral bodies.

\section{Surgical procedures}

All the patients were treated with anterior radical debridement, and their anterior spinal column was supported with a tricortical iliac bone graft (12 patients) or titanium mesh (10 patients). Posterior pedicle screw instrumentation was performed in 17 of 22 patients. Posterior surgery was performed 1 or 2 weeks after the anterior surgery in 16 of 17 patients, or as single stage procedure in 1 patient. The combination of surgeries were anterior strut bone and posterior pedicle screws in 12 patients, anterior titanium mesh and posterior pedicle screws in 5 patients and anterior mesh only in 5 patients. The anterior mesh only option was used in the 5 patients who had one segment involvement in the thoracic spine ( 3 patients) or for those patients could not withstand second surgery due to their poor medical condition (2 patients). Histopathological examination and cultures for acid-fast bacilli were performed for making a confirmative diagnosis of tuberculosis postoperatively. The patients were allowed to ambulate after the surgeries with wearing a plastic body jacket brace.

\section{Follow-up evaluations}

The patients were followed up with assessing the laboratory inflammatory parameters, the serial plain radiographs, the neurological recovery and the clinical outcome. The erythrocyte sedimentation rate and the C-reactive protein level of the patients were checked periodically. The regional kyphotic angle of the affected lesion was measured by Cobb's method between the most tilted vertebrae on the standing lateral radiographs. The presence of migration or breakage of implants was carefully inspected for. Marked shortening, migration, absorption or fracture of a tricortical bone graft was considered as failure of union, and trabecular rearrangement and hypertrophy of a graft was considered as successful union. Fusion of a titanium mesh cage was assessed by the absence of motion in the fused segment on the dynamic radiographs, a loosening or hollow sign around the implant, and cage breakage or migration. Recovery from neurological impairments was evaluated by Frankel's grading system. The clinical outcomes were evaluated by the criteria of Kim and Lee ${ }^{10}($ Table 2$)$.

\section{Statistical analysis}

Statistical analyses were conducted with SPSS ver. 10.0 (SPSS Inc., Chicago, IL, USA). The Mann-Whitney test was used for the analysis of the differences in the amount of correction and the loss of correction between the older patient group (fifty years old or more) and the younger patient group (fifty years old or less). The differences in the amount of correction and the loss of correction between the monosegmental involvement group and the multisegmental involvement group were also analyzed by using the MannWhitney test. The significance of the differences between more than two groups was determined by the Kruskal-Wallace analysis of variance test, and this was used for comparison of the operation methods (mesh only, mesh and pedicle screws, and tricortical iliac bone and pedicle screws) and the involved region (thoracic, thoracic and lumbar, and lumbar). A p-value of $<0.05$ was considered statistically significant.

\section{Results}

\section{Laboratory assessment}

The erythrocyte sedimentation rates were preoperatively checked in 18 of 22 patients and they were increased in 15 patients $(83 \%)$. The erythrocyte sedimentation rates were normalized at an average of 7.8 months (range, 1 to 12 months) after surgery. The levels of C-reactive protein were checked preoperatively in 17 of 22 patients and they were 
Table 2. Criteria for clinical outcome

\begin{tabular}{ll}
\hline Excellent & Complete relief of pain in back and lower limbs \\
& No limitation of physical activity \\
& Analgesics not used \\
& Able to squat on the floor \\
& Relief of most pain in back and lower limbs \\
& Able to return to accustomed employment \\
Good & Physical activities slightly limited \\
& Analgesics used only infrequently \\
& Able to squat on the floor \\
& Able to return to accustomed employment with limitation, or return to lighter work \\
& Physical activities definitely limited \\
Fair & Mild analgesic medication used frequently \\
& Mild limitation to squat on the floor \\
& Little or no relief of pain in back and lower limbs \\
& Physical activities greatly limited \\
Poor & Unable to return to accustomed employment \\
& Analgesic medication used regularly \\
& Unable to squat on the floor without support \\
\hline
\end{tabular}

Table 3. Changes of regional kyphosis angle $\left(^{\circ}\right)$

\begin{tabular}{|c|c|c|c|c|c|c|c|c|}
\hline \multirow[b]{2}{*}{ Groups } & \multicolumn{8}{|c|}{ Kyphosis angle $\left({ }^{\circ}\right)$} \\
\hline & Preop. & Postop. & Correction & $\begin{array}{l}\text { Percentage } \\
\text { of correction }\end{array}$ & $\begin{array}{l}\text { Final F/U } \\
\text { follow-up }\end{array}$ & $\begin{array}{l}\text { Correction } \\
\text { loss }\end{array}$ & $\begin{array}{l}\text { Percentage of } \\
\text { correction loss }\end{array}$ & $\begin{array}{c}\text { Final } \\
\text { correction }\end{array}$ \\
\hline \multicolumn{9}{|l|}{ Operation Methods } \\
\hline $\operatorname{Mesh}(n=5)$ & $\begin{array}{c}15.6 \\
(-11 \text { to } 39)\end{array}$ & $\begin{array}{c}10.6 \\
(-21 \text { to } 36)\end{array}$ & $\begin{array}{c}5.0 \\
\text { (1 to } 10)\end{array}$ & $32 \%$ & $\begin{array}{c}15.4 \\
(-14 \text { to } 47)\end{array}$ & $\begin{array}{c}4.8 \\
\text { (0 to } 11)\end{array}$ & $96 \%$ & $\begin{array}{c}0.2 \\
\text { (-8 to } 3)\end{array}$ \\
\hline $\begin{array}{l}\text { Mesh+PS } \\
(n=5)\end{array}$ & $\begin{array}{c}21.2 \\
(-13 \text { to } 39)\end{array}$ & $\begin{array}{c}11.0 \\
(-29 \text { to } 37)\end{array}$ & $\begin{array}{c}10.2 \\
\text { (2 to } 21)\end{array}$ & $48 \%$ & $\begin{array}{c}18.6 \\
(-24 \text { to } 42)\end{array}$ & $\begin{array}{c}7.6 \\
(-1 \text { to } 21)\end{array}$ & $75 \%$ & $\begin{array}{c}2.6 \\
(-5 \text { to } 11)\end{array}$ \\
\hline $\begin{array}{l}\text { Bone graft+PS } \\
(\mathrm{n}=10)\end{array}$ & $\begin{array}{c}13.8 \\
(-26 \text { to } 48)\end{array}$ & $\begin{array}{c}3.8 \\
(-23 \text { to } 32)\end{array}$ & $\begin{array}{c}9.9 \\
(-3 \text { to } 31)\end{array}$ & $72 \%$ & $\begin{array}{c}10.1 \\
(-21 \text { to } 38)\end{array}$ & $\begin{array}{c}6.3 \\
\text { (2 to } 15)\end{array}$ & $64 \%$ & $\begin{array}{c}3.7 \\
(-15 \text { to } 20)\end{array}$ \\
\hline \multicolumn{9}{|l|}{ Involved region } \\
\hline $\begin{array}{l}\text { Thoracic } \\
(\mathrm{n}=11)\end{array}$ & $\begin{array}{c}30.5 \\
\text { (9 to } 48)\end{array}$ & $\begin{array}{c}24.0 \\
\text { (8 to } 37)\end{array}$ & $\begin{array}{c}6.5 \\
\text { (0 to } 17)\end{array}$ & $21 \%$ & $\begin{array}{c}28.4 \\
\text { (8 to } 47)\end{array}$ & $\begin{array}{c}4.4 \\
(-1 \text { to } 11)^{*}\end{array}$ & $68 \%$ & $\begin{array}{c}2.1 \\
(-8 \text { to } 14)\end{array}$ \\
\hline $\begin{array}{l}\text { Thoracolumbar } \\
(n=4)\end{array}$ & $\begin{array}{c}27.0 \\
\text { (21 to } 32\end{array}$ & $\begin{array}{c}10.5 \\
(-2 \text { to } 20)\end{array}$ & $\begin{array}{c}16.5 \\
\text { (1 to } 31)\end{array}$ & $61 \%$ & $\begin{array}{c}22.5 \\
(13 \text { to } 32)\end{array}$ & $\begin{array}{c}12.0 \\
(5 \text { to } 21)^{\star}\end{array}$ & $73 \%$ & $\begin{array}{c}4.5 \\
(-4 \text { to } 16)\end{array}$ \\
\hline Lumbar $(n=7)$ & $\begin{array}{c}-13.4 \\
(-26 \text { to } 4)\end{array}$ & $\begin{array}{c}-21.7 \\
(-29 \text { to }-14)\end{array}$ & $\begin{array}{c}8.3 \\
(-3 \text { to } 24)\end{array}$ & $62 \%$ & $\begin{array}{c}-15.9 \\
(-24 \text { to }-7)\end{array}$ & $\begin{array}{c}5.9 \\
\text { (2 to } 12)\end{array}$ & $71 \%$ & $\begin{array}{c}2.4 \\
(-15 \text { to } 20)\end{array}$ \\
\hline \multicolumn{9}{|l|}{ Age of patients } \\
\hline $\begin{array}{l}<50 \text { years old } \\
(\mathrm{n}=11)\end{array}$ & $\begin{array}{c}23.6 \\
(-13 \text { to } 48)\end{array}$ & $\begin{array}{c}12.2 \\
(-29 \text { to } 37)\end{array}$ & $\begin{array}{c}11.5 \\
(0 \text { to } 31)\end{array}$ & $48 \%$ & $\begin{array}{c}17.8 \\
(-24 \text { to } 42)\end{array}$ & $\begin{array}{c}5.6 \\
(-1 \text { to } 15)\end{array}$ & $49 \%$ & $\begin{array}{c}5.8 \\
(-6 \text { to } 20)\end{array}$ \\
\hline $\begin{array}{l}\geq 50 \text { years old } \\
(n=9)\end{array}$ & $\begin{array}{c}4.7 \\
(-26 \text { to } 39)\end{array}$ & $\begin{array}{c}-0.4 \\
(-23 \text { to } 36)\end{array}$ & $\begin{array}{c}5.1 \\
(-3 \text { to } 21)\end{array}$ & $109 \%$ & $\begin{array}{c}6.7 \\
(-21 \text { to } 47)\end{array}$ & $\begin{array}{c}7.1 \\
\text { (0 to } 21)\end{array}$ & $139 \%$ & $\begin{array}{c}-2.0 \\
(-15 \text { to } 5)\end{array}$ \\
\hline \multicolumn{9}{|l|}{ Involved segment } \\
\hline $\begin{array}{l}1 \text { Segment } \\
(=6)\end{array}$ & $\begin{array}{c}11.7 \\
(-13 \text { to } 29)\end{array}$ & $\begin{array}{c}-1.0 \\
(-22 \text { to } 20)\end{array}$ & $\begin{array}{c}12.7 \\
(1 \text { to } 31)\end{array}$ & $109 \%$ & $\begin{array}{c}3.8 \\
(-18 \text { to } 24)\end{array}$ & $\begin{array}{c}4.8 \\
\text { (0 to } 15)\end{array}$ & $38 \%$ & $\begin{array}{c}7.8 \\
\text { (1 to } 20)\end{array}$ \\
\hline $\begin{array}{l}\geq 2 \text { Segment } \\
(n=16)\end{array}$ & $\begin{array}{c}17.4 \\
(-26 \text { to } 48)\end{array}$ & $\begin{array}{c}10.0 \\
(-29 \text { to } 37)\end{array}$ & $\begin{array}{c}7.4 \\
(-3.0 \text { to } 21)\end{array}$ & $43 \%$ & $\begin{array}{c}16.8 \\
(-24 \text { to } 47)\end{array}$ & $\begin{array}{c}6.8 \\
(-1 \text { to } 21)\end{array}$ & $92 \%$ & $\begin{array}{c}0.7 \\
(-15 \text { to } 14)\end{array}$ \\
\hline
\end{tabular}

All values are expressed as mean (range), Mesh: titanium mesh cage, PS: pedicle screw.

${ }^{*}$ Statistically significant difference between two groups based on Kruskall-Wallis test $(\mathrm{p}=0.050)$ and Tukey's multiple comparison test. 

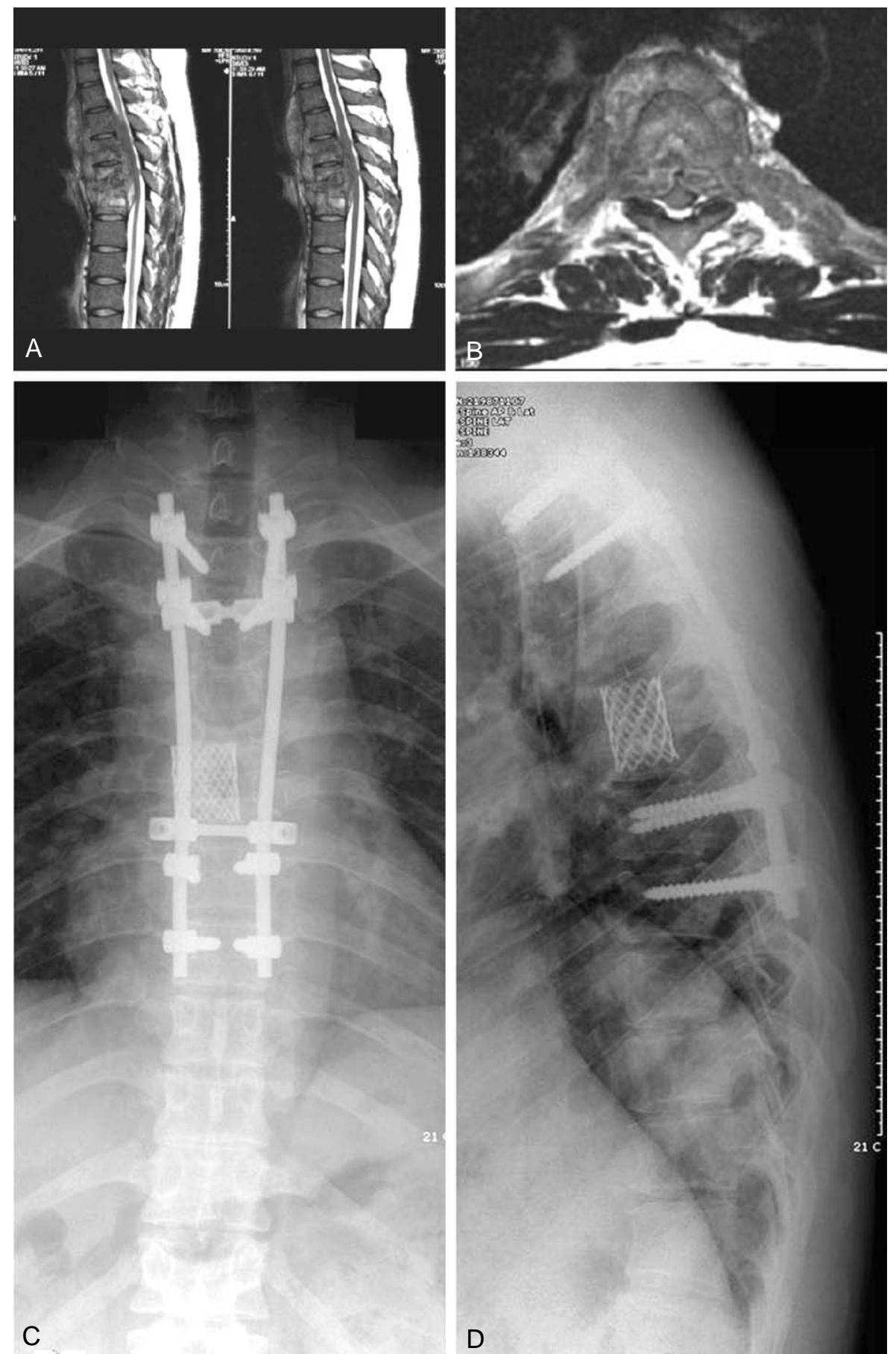

Fig. 1. A 28-year-old man with tuberculous spondylitis was treated with anterior debridement and mesh insertion followed by posterior pedicle screw instrumentation. An extensive destructive lesion of the thoracic spine that mainly affected T5-6 level was noted on the sagittal T2-weighted (A) and axial (B) magnetic resonance images. The anteroposterior (C) and lateral (D) radiographs obtained 3 -years after operation show the normal sagittal contour of the thoracic spine without focal kyphosis.

increased in 16 patients (94\%). The levels of C-reactive protein were normalized at a postoperative mean of 5.4 months (range, 1 to 12 months). The erythrocyte sedimentation rates and the C-reactive protein levels were eventually normalized during the follow-up in all the patients.

\section{Radiologic evaluation}

The overall correction of kyphotic deformity, as measured by Cobb's method, was initially 8.9 degrees, and the loss of correction was 6.2 degrees. The amount of correc- 

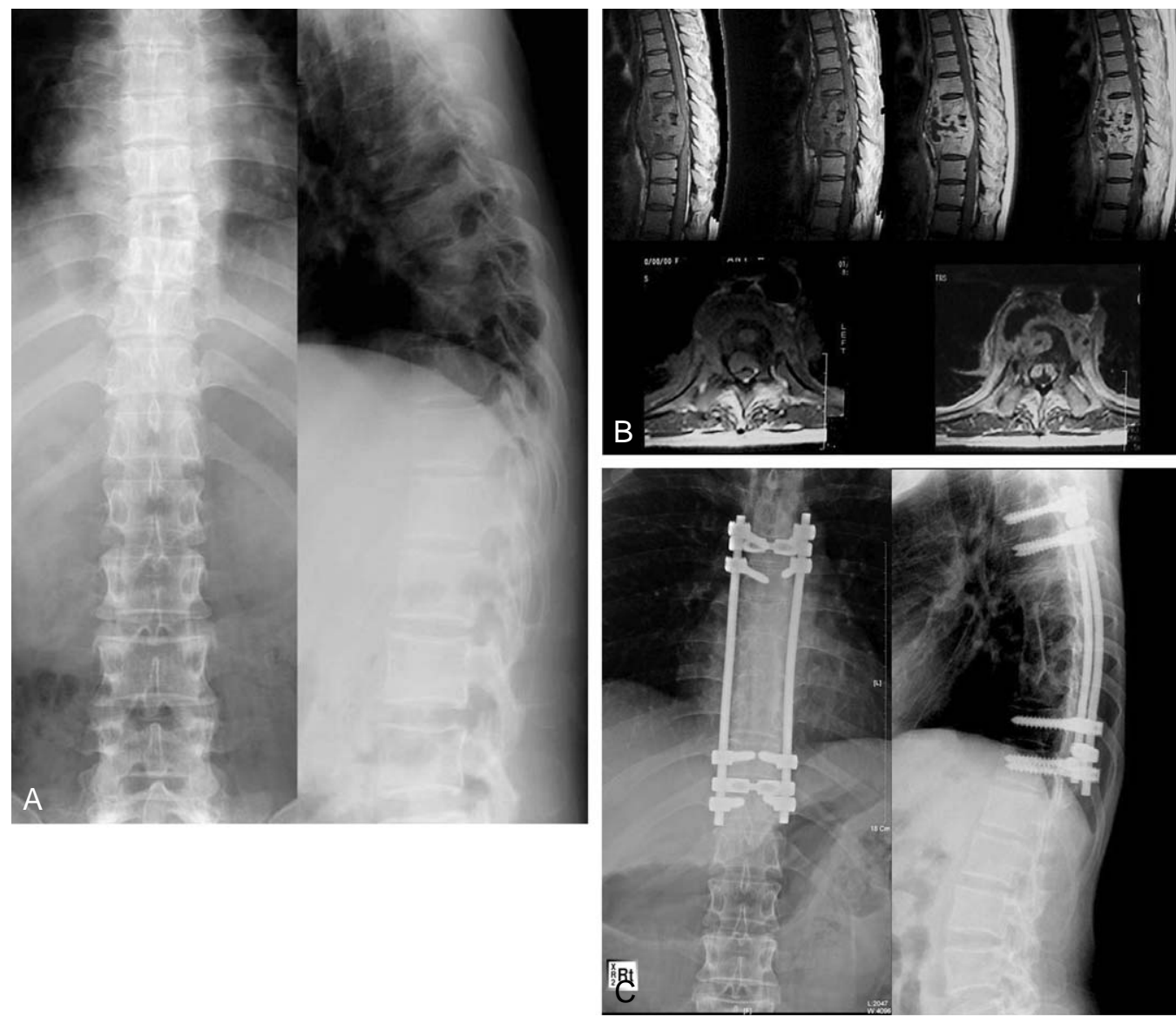

Fig. 2. The preoperative plain AP and lateral radiographs of a 31-year-old woman show a T8 lesion with bone destruction and disc space narrowing at the T8-9 level (A). The magnetic resonance images show destructive lesion at T7, T8 and T9 along with a paraspinal abscess (B). She was treated with anterior debridement and bone graft followed by posterior pedicle screw instrumentation. The radiographs obtained at postoperative 4-years show consolidation of the bone graft and the normal sagittal contour of the thoracic spine.

tion and the loss of correction were statistically analyzed according to some variables, such as the operation methods, the involved region, the patients' age and the number of involved segments (Table 3). The average amounts of correction were not influenced according to such variables as the operation methods, the involved region, the patient's age and the number of involved segments ( $p>0.05)$. In terms of the loss of correction during the follow-up, it was significantly different according to the involved region (thoracic vs. thoracolumbar), but it was not influenced by the operation methods, the patients' age or the number of involved segments. The loss of correction was significantly larger for the thoracolumbar lesion than that for the thoracic lesion $(\mathrm{p}=0.050)$.

There was no case of breakage of the pedicle screws, rods or titanium mesh. However, mild anterior migration of mesh during the initial follow up was noted in 2 patients who had lesion involvement of more than 2 segments and these were not fixed with posterior pedicle screws. Consolidation of the graft bone was observed in all the 12 patients who were treated by an anterior strut bone graft and posterior pedicle screw instrumentation. Any collapse, resorption or lucency at the bone-graft junction of the iliac strut graft was not observed.

\section{Neurological and clinical outcomes}

The preoperative Frankel grades were B for 1 patient, C for 4 patients, $\mathrm{D}$ for 4 patients and $\mathrm{E}$ for 13 patients. At the final follow-up, 7 of the 9 neurologically-compromised patients recovered completely to Frankel grade E and only two patients showed Frankel grade D. The preoperative Frankel grades of these two patients were B and D, respectively. One of these patients had paraparesis below the T11 level with lower extremity total motor paralysis and decreased sensation below T11 (Grade B) before surgery, 
and this patient had improvement to Grade D during the follow-up. His motor recovery became evident 15 days after surgery and self voiding was restored 48 days postoperatively (Case 22). The other patient had a neurological deficit (Grade D), but surgery was delayed for 2 weeks due to the patient's poor medical condition. There was no change in his neurologic status after surgery (Case 19).

The clinical outcomes were excellent for 5 patients, good for 12 patients and fair for 5 patients. Satisfactory results (excellent or good) were obtained for 17 (77\%) of 22 patients.

\section{Complications}

No patients died of postoperative complications. The complications were postoperative superficial wound infection in 1 patient, mild anterior migration of the titanium mesh in 2, transient lower extremity edema in 1 and recurrence of psoas abscess in 1. A patient who had a superficial wound infection was treated by debridement and re-suture (Case 13). Mild anterior migration (less than 1/4 of the vertebral AP width) of the titanium mesh was observed in two patients who had multilevel disease and who were not fixed with pedicle screws (Cases 20 and 22). Migration of the mesh occurred during the first 6 months in both these patients. They did not undergo any additional surgery because the migration did not progress and they did not show instability on the dynamic radiographs nor did they have significant back pain. Transient lower extremity edema developed in a young patient without any evidence of vascular or lymphatic injury during anterior surgery and it spontaneously resolved at postoperative 3 months (Case $3)$. One patient was complicated with a recurrent psoas abscess (Case 5). She was initially treated by anterior debridement and titanium mesh insertion, followed by posterior pedicle screw instrumentation; the recurrence of the abscess in the psoas muscle was found on the MRI followup at postoperative 7 months. It was percutaneously drained by CT-guided insertion of a pig-tail catheter and the patient was successfully cured by a combination of drainage and continuous anti-tuberculous chemotherapy.

\section{Discussion}

Modern anti-tuberculous chemotherapy has revolution- ized the treatment of tuberculous spondylitis, but residual kyphosis with or without neurologic deficit is a possible complication after conservative treatment. The British Medical Research Council Working Party on Tuberculosis of the Spine performed a large scale, controlled trial of various treatment methods ${ }^{11-13}$. They concluded that chemotherapy was an effective treatment for the majority of the patients with tuberculous spondylitis ${ }^{11,13}$. However, kyphotic deformity and delayed bony union are possible complications of conservative treatment ${ }^{11,13}$.

Since Hodgson and Stock ${ }^{1}$ first reported on radial debridement and anterior fusion, it has been advocated as the treatment of choice for the patients with tuberculous spondylitis. It has the advantages of direct access to the focus of infection, the ability to effectively decompress the neural tissue, and it can stabilize the spine by a strut bone graft. However, graft slippage, resorption, subsidence and fracture of the graft were observed by many surgeons and the subsequent increased incidence of kyphosis was report$\mathrm{ed}^{3,14}$. Kim et al. ${ }^{15}$ reported the results of radical debridement and anterior iliac bone grafting in 140 patients. In their series, the kyphosis correction was $55.1 \%$ just after surgery, and the correction of the initial angle was decreased to $7.5 \%$ at 2 years after surgery. Rajasekaran and Soundarapandian ${ }^{3}$ suggested that the patients having a graft longer than two disc spaces might benefit from additional measures for preventing graft collapse, such as an extended period of nonweight bearing, the performance of posterior arthrodesis and the prolonged use of a brace.

To prevent increasing kyphosis after anterior fusion, supplementary posterior fusion and instrumentation have been advocated by many surgeons ${ }^{5,7-9}$. Moon et al. ${ }^{5}$ reported that posterior instrumentation after anterior fusion was helpful in providing early fusion and preventing the progression of kyphosis. They used various posterior instruments such as a hook and rod system or a rod and segmental wiring technique. The collapsed vertebrae regained their height with these procedures and the correction was successfully maintained. However, Harrington instrumentation or segmental wiring has bio-mechanically weaker holding power than the modern pedicle screw system, and the former techniques usually need more levels of instrumentation for the purpose of decreasing the abnormally high stress on the metal or bone lamina. Actually, pedicle screws have strong biomechanical holding power on the anterior column as well as on the posterior column, which can effectively share the anterior load on the spinal column. The posteriorly instrumented 
pedicle screw system could distribute the load to the anterior column and possibly decrease the number of fusion levels. We have started to use the pedicle screw system in patients with tuberculous spondylitis after anterior debridement and arthrodesis as early as the late 1980s. In the thoracic region, where the segmental motion is not so large, we preferred fusing two vertebrae above and below the affected lesion. In the lumbar region, where we try to save the segmental motion as much as possible, we usually fused one vertebra above and one below the lesion.

Güven et al. ${ }^{9}$ reported an average of 3.4 degrees loss of correction after posterior drainage and Cotrel-Dubousset instrumentation. Moon et al..$^{5}$ reported on the results of anterior arthrodesis and the posterior Harrington or segmental wiring technique, and the loss of correction did not exceed 3 degrees in their series. Chen et al. ${ }^{8}$ used the Harrington technique or Luque instrumentation after anterior iliac strut grafting, and they observed less than 3 degrees loss of the initial correction. In our current series, the loss of correction during the follow-up was an average of 6.2 degrees despite performing pedicle screw instrumentation. It may be due to the relatively short length of the instrumented levels with our technique and the immediate ambulation of the patients without using a heavy immobilizing cast or brace. Even though the average loss of correction in our series was slightly higher than that of the previous studies that used posterior implants ${ }^{5,8.9}$, we did not experience any unsightly increasing kyphosis or metal failure after the use of pedicle screws. A slight increase of the correction loss is a matter of making numeric measurement on the radiographs and it did not bring about cosmetic or functional problems in our patients. The patients in our series were able to ambulate wearing a light plastic brace immediately after stabilizing the spine with the implants.

We started to use the titanium mesh as early as the early 1990s in patients who had tuberculous spondylitis with a large bone defect and who were proven not to have active liquefied pus in the surgical field at the time of anterior debridement. Many recent studies have reported that titanium mesh cages were an effective and safe anterior column reconstruction method for tuberculous ${ }^{16}$ and even for septic spondylitis ${ }^{17,18}$. We have found that usage of a mesh cage usage in patients with tuberculous spondylitis does not inhibit control of infection, but we are still reluctant to use it in patients with pyogenic spondylitis. Titanium mesh in patients with tuberculous spondylitis eliminated a need for iliac bone harvesting because we filled the mesh with resected rib bone that was acquired during the transthoracic and thoracoabdominal approaches. We sometimes did not perform additional posterior surgery after anterior mesh insertion. In the case of short segment involvement in the thoracic region, a titanium cage filled with rib bone was a good option for anterior reconstruction, and this eliminated the need for iliac bone harvesting or posterior instrumentation. A plastic thoracolumboscral orthosis brace was good enough to support the thoracic spine because a rib cage acts as the fourth column of the spine in this region. However this titanium mesh only option without posterior instrumentation seemed to be somewhat unstable in patients with multi-segmental involvement. We observed mild migration of the mesh in the patients who had multilevel involvement, but we had to omit posterior fixation due to the patients' poor general condition. We do not now recommend the titanium mesh only option for the multi-segmental involvement cases. Titanium mesh was an especially useful alternative to strut bone grafting for the patients who had multilevel involvement with a long segmental defect after anterior debridement and there was a need to harvest a long length of structural graft. It was also helpful for patients who had osteoporosis with poor iliac bone quality. For this population of patients, a strut bone graft for anterior column reconstruction can have suboptimal mechanical strength.

Statistical analyses showed that the amount of surgical correction and the loss of correction during follow up was not influenced by the operation method, the patient's age and the number of involved segments. The loss of correction was greater in the thoracolumbar region than that in the thoracic region. The thoracolumbar junction is well known as an area of concentrated stress due to the biomechanical transition from a stiff thoracic spine to a mobile lumbar spine. This biomechanical fact could contribute to the high loss of correction in the thoracolumbar region. Krompinger et al reported that $36 \%$ of the spine fractures at the thoracolumbar junction progressed 10 degrees or more at followup, whereas no thoracic facture and only one lumbar fracture progressed 10 degrees or more ${ }^{19}$. There were no statistical differences among three kinds of operation methods, such as mesh only, posterior pedicle screws after anterior bone grafting, and pedicle screw after anterior mesh, regarding the surgical correction and the loss of correction. However, this may be due to the small number of patients in each group of our series, and further studies with a larger number of patients are needed.

Yilmaz et al. ${ }^{6}$ believed that anterior instrumentation is 
more effective than posterior instrumentation for reducing the deformity and stabilizing the vertebral column in patients who have kyphosis due to spinal tuberculosis. They used rods and screws placed in the vertebral bodies that extended one level cephalad and one level caudal to the affected vertebrae. The average correction of deformity was $64 \%$ in the patients with one or two levels of involvement and it was $81 \%$ for the patients with more than two levels of involvement. The maximal loss of correction was 3 degrees. They did not experience recurrence of disease. We put in the titanium mesh during the anterior surgery, but we did not insert an anterior screw device at the same time. For anterior instrumentation of the spine with using a screw system, a surgeon needs to extend the surgical dissection to the healthy vertebra for inserting the screw system in the cephalad or caudal direction. This usually requires more extended dissection of vital structures, including the large vessels adjacent to the vertebral column; moreover, if there is some infectious adhesion of the paravertebral structures, then the surgical dissection is even more difficult. Moreover, if the infection extends, after surgery, to the adjacent vertebra where the screws were inserted, then failure of fixation can lead to an anterior catastrophic result. For these reasons, we minimized the extent of the anterior surgery on the affected vertebra and we did not fixate the spine with using an anterior screw system for stabilization, even though singlestaged anterior instrumentation has many benefits. Posterior instrumentation also can minimize the burden of metallic foreign bodies at the focus of infection and it can maximize the stability of the spine by the formation of a posterior tension band.

The anterior surgical approach has advantages of direct access and excision of the lesion with the ability to decompress the neural elements ${ }^{3,20}$. Although some authors have reported a good clinical result for performing posterior transpedicular drainage and instrumentation in the patients who had tuberculosis of the spine without neurologic involvement ${ }^{9}$, we believe anterior debridement and arthrodesis are indispensable for achieving successful surgical treatment of the patients with neurologic deficits. In our series, the neurologic deficits of the patients disappeared after anterior surgery in the most of the cases.

In principle, metallic implants or foreign bodies are contraindicated at the site of musculoskeletal infection. There is a fear of persistent infection around the metal that is caused by preferential adhesive bacterial colonization on an inert surface. Oga et al. ${ }^{4}$ reported that microorganisms such as
Staphylococcus epidermis attach to the inert surface and colonize it, and then they produce an extrapolysaccharide biofilm that protects the organism from host defense mechanisms and antibiotics. However they found that mycobacterium tuberculosis was less adhesive, and they observed only a few biofilm-covered microcolonies around the stainless steel in vitro. They suggested that mycobacterium may have different adhesive properties and adhesive action to biomaterial surfaces than do other bacteria and mycobacterium may produce less biofilm. Clinically, they also did not experience persistent or recurrence of infection after anterior radical surgery followed by posterior instrumentation. Several other authors have subsequently reported clinical studies that have supported the microbiological safety of using metallic implants in patients with tuberculous spondylitis ${ }^{5,68,9,21}$. In our series, we had no case of persist infection when the patients were treated by surgeries with using metallic implants and anti-tuberculous combination chemotherapy. The inflammatory parameters such as the erythrocyte sedimentation rate and the C-reactive protein level were eventually normalized in our patients and the use of metallic implants did not inhibit control of tuberculous infection. We also did not experience any late recurrence of infection.

\section{Conclusions}

Stabilizing the spine with pedicle screws and titanium mesh effectively prevented the development of kyphotic deformity in patients with tubercuous spondylitis of the thoracic and lumbar spine and this technique provided immediate postoperative ambulation. The metallic implants did not prohibit control of infection when combined with radical debridement and anti-tuberculous chemotherapy.

\section{REFERENCES}

1. Hodgson AR, Stock FE: Anterior Spine Fusion for the Treatment of Tuberculosis of the Spine. J Bone Joint Surg 1960; 42: 295-310.

2. Kemp HB, Jackson JW, Jeremiah JD, Cook J: Anterior fusion of the spine for infective lesions in adults. J Bone Joint Surg Br 1973; 55: 715-734.

3. Rajasekaran S, Soundarapandian S: Progression of kyphosis in tuberculosis of the spine treated by anterior 
arthrodesis. J Bone Joint Surg Am 1989; 71: 1314-1323.

4. Oga M, Arizono T, Takasita M, Sugioka Y: Evaluation of the risk of instrumentation as a foreign body in spinal tuberculosis. Clinical and biologic study. Spine 1993; 18: 1890-1894.

5. Moon MS, Woo YK, Lee KS, Ha KY, Kim SS, Sun DH: Posterior instrumentation and anterior interbody fusion for tuberculous kyphosis of dorsal and lumbar spines. Spine 1995; 20: 1910-1916.

6. Yilmaz C, Selek, HY, Gurkan I, Edermli B, Korkusuz $\mathbf{Z}$ : Anterior instrumentation for the treatment of spinal tuberculosis. J Bone Joint Surg Am 1999; 81: 1261-1267.

7. Chen WJ, Chen CH, Shih CH: Surgical treatment of tuberculous spondylitis. 50 patients followed for 2-8 years. Acta Orthop Scand 1995; 66: 137-142.

8. Chen WJ, Wu CC, Jung CH, Chen LH, Niu CC, Lai PL: Combined anterior and posterior surgeries in the treatment of spinal tuberculous spondylitis. Clin Orthop Relat Res 2002; 398: 50-59.

9. Guven O, Kumano K, Yalcin S, Karahan M, Tsuji S: A single stage posterior approach and rigid fixation for preventing kyphosis in the treatment of spinal tuberculosis. Spine 1994; 19: 1039-1043.

10. Kim NH, Lee JW: Anterior interbody fusion versus posterolateral fusion with transpedicular fixation for isthmic spondylolisthesis in adults. A comparison of clinical results. Spine 1999; 24: 812-816.

11. A controlled trial of ambulant out-patient treatment and inpatient rest in bed in the management of tuberculosis of the spine in young Korean patients on standard chemotherapy a study in Masan, Korea. First report of the Medical Research Council Working Party on Tuberculosis of the Spine. J Bone Joint Surg Br 1973; 55: 678-697.

12. A controlled trial of anterior spinal fusion and debridement in the surgical management of tuberculosis of the spine in the patients on standard chemotherapy: a study in Hong Kong. Br J Surg 1974; 61: 853-866.

13. A five-year assessment of controlled trials of in-patients and out-patient treatment and of plaster-of-Paris jackets for tuberculosis of the spine in children on standard chemotherapy. Studies in Masan and Pusan, Korea. Fifth report of the Medical Research Council Working Party on Tuberculosis of the Spine. J Bone Joint Surg Br 1976; 58B: 399-414.

14. Bailey HL, Gabriel M, Hodgson AR, Shin JS: Tuberculosis of the spine in children. Operative findings and results in one hundred consecutive patients treated by removal of the lesion and anterior grafting. J Bone Joint Surg Am 1972; 54: 1633-1657.

15. Kim BJ, Ko HS, Lim Y, Seo JG, Jeon TH: The clinical study of the tuberculous spondylitis. J Korean Orthop Assoc 1993; 28: 2221-2232.

16. Christodoulou AG, Givissis P, Karataglis D, Symeonidis PD, Pournaras J: Treatment of tuberculous spondylitis with anterior stabilization and titanium cage. Clin Orthop Relat Res 2006; 444: 60-65.

17. Korovessis P, Petsinis G, Koureas G, IIiopoulos P, Zacharatos S: Anterior surgery with insertion of titanium mesh cage and posterior instrumented fusion performed sequentially on the same day under one anesthesia for septic spondylitis of thoracolumbar spine: is the use of titanium mesh cages safe? Spine 2006; 31: 1014-1019.

18. Korovessis P, Petsinis G, Koureas G, Iliopoulos P, Zacharatos S: One-stage combined surgery with mesh cages for treatment of septic spondylitis. Clin Orthop Relat Res 2006; 444: 51-59.

19. Krompinger WJ, Fredrickson BE, Mino DE, Yuan HA: Conservative treatment of fractures of the thoracic and lumbar spine. Orthop Clin North Am 1986; 17: 161-170.

20. Kim BJ, Ko HS, Lim Y, Seo JK, Choi JY, Suh JS: Surgical treatment of paraplegia in spinal tuberculosis. J Korean Orthop Assoc 1993; 28: 1595-1602.

21. Ha KY, Chung YG, Ryoo SJ: Adherence and biofilm formation of Staphylococcus epidermidis and Mycobacterium tuberculosis on various spinal implants. Spine 2005; 30: 38-43. 